\title{
Genetic variation and selection for fertility in the fungus Cochliobolus heterostrophus
}

\author{
James A. Kolmer and \\ Kurt J. Leonard
}

Department of Plant Pathology, North Carolina State University; United States Department of Agriculture, Raleigh N.C. 27695-7616, U.S.A.

The response to selection for perithecial number in Cochliobolus heterostrophus, a heterothallic ascomycete, is described. Thirteen $M A T A$ isolates and $12 \mathrm{MATa}$ isolates of the fungus were mated in all possible combinations and evaluated for fertility. Progeny from some of these matings segregated for a defective perithecial allele. Selection for increased numbers of mature perithecia was carried out for six generations of intermatings among four to six parents in each generation which were selected from approximately 24 progeny from the preceeding generation. After six generations the numbers of perithecia had increased by nearly a factor of four. The proportion of additive genetic variance decreased linearly in the selection generations. The increase in perithecia was confirmed in concurrent mating tests among subpopulations from each selection generation.

\section{INTRODUCTION}

Quantitative genetic variation has received little attention in studies of the genetics of plant pathogenic fungi although it is thought to be important in determining the parasitic abilities of these organisms. Cochliobolus heterostrophus Drechsler, the causal agent of southern corn leaf blight, is a heterothallic fungus with two mating type alleles, MATA and MATa, required for sexual reproduction in pairings between haploid isolates (Nelson, 1957). Nelson (1959a) observed differences in numbers of perithecia produced in matings of sexually compatible isolates of the fungus, but did not quantitatively analyse these heritable differences in fertility. Nelson (1959b) later identified a single gene in naturally occurring isolates that can eliminate or greatly reduce perithecial production when it is present in both members of a pair of sexually compatible isolates of the fungus. In studies with other species of Cochliobolus, Nelson and others demonstrated that fertility is controlled by genes other than the two alleles at the mating type locus (Nelson, 1961; 1964; 1970; Kline and Nelson, 1968), but the role of polygenic variation was not rigorously examined.

Paper number 9714 of the journal series of the North Carolina Agricultural Research Service.
Selection experiments have been used to demonstrate polygenic variation for various traits in fungi. In Aspergillus nidulans, penicillin titer was doubled after four generations of recurrent selection (Merrick, 1976). Selection in both directions over several generations for hyphal growth rate was effective in Neurospora crassa (Papa, Srb and Federer, 1966). Similar results were found for growth rate in Schizophyllum commune (Simchen, 1966). The response to selection in these studies was evidence of polygenic variation influencing these traits. The present study was undertaken to determine the nature of the genetic control of perithecial number in Cochliobolus heterostrophus Drechsler. The extent of polygenic variation present in the fungus which influences fertility was tested by means of recurrent selection for increased perithecial number.

\section{MATERIALS AND METHODS}

\section{Initial population}

Thirteen MATA and 12 MATa isolates were chosen from a group of conidial isolates collected from diseased corn leaves from fields in North Carolina or from first generation ascospore progeny obtained from crosses of such isolates. The 
25 isolates were paired in all possible combinations. All parental and progeny isolates in this study were stored at $4^{\circ} \mathrm{C}$ in potato dextrose agar (PDA) slants. The fungal isolates were grown on PDA containing $10 \mathrm{~g}$ dextrose per litre for 4 days after which small $(2-4 \mathrm{~mm})$ blocks of agar with the fungus were transferred to petri dishes filled with Sach's agar. Isolates of compatible mating types were placed opposite of each other across autoclaved, $1 \mathrm{~cm}$ diametre, senescent corn leaf disks in the Sach's agar petri dishes. Four leaf disks per petri dish were used for each MATA $\times M A T a$ isolate combination. All crosses were kept in the dark at $25^{\circ} \mathrm{C}$ for 14 days. Mature perithecia that developed on the corn leaf disks were counted, with each leaf disk representing one replication.

\section{Selection for fertility}

The two to three most fertile MATA and the two to three most fertile MATa isolates (as expressed by the average number of mature perithecia the isolate produced in crosses with all isolates of the compatible mating type) were selected as parents for the next generation. Ascospore progeny were isolated from the selected crosses, evaluated for mating type, and then crossed in all possible combinations to form the next selection generation. Approximately 12 isolates of each mating type were used in each selection generation. Selection was carried out for six generations.

\section{Evaluation of subpopulations}

To provide a control for the selection experiment, subpopulations of each generation were evaluated in common environments. Four or five isolates of each mating type in each generation were randomly chosen and crossed with compatible isolates of the same generation. In three separate tests, subpopulations from the initial generation and selection generations one, two, and three; generations three, four and five; generations four, five and six, respectively, were evaluated in common environments.

\section{Analysis of genetic variance}

The model, Number of perithecia per isolate pair = mean effects of isolate $M A T A+$ mean effects of isolate $M A T A+$ specific interactions between isolate MATA and isolate MATa, was used to estimate the additive and additive $\times$ additive genetic variances in all generations. The genetic variance was partitioned using North Carolina Design II
Table 1 North Carolina Design II. Sources of variation and expected mean squares

\begin{tabular}{lll}
\hline Source & d.f. & Expected mean square \\
\hline Isolates MATA & $A-1$ & $V_{e}+(4) V_{A \times a}(4 a) V_{M A T A}$ \\
Isolates MATa & $a-1$ & $V_{e}+(4) V_{A \times a}(4 A) V_{M A T a}$ \\
$M A T A \times M A T a$ & $(A-1)(a-1)$ & $V_{e}+(4) V_{A \times a}$ \\
Error & $A a(4-1)$ & $V_{e}$ \\
\hline
\end{tabular}

as modified for inbred lines (Eberhart, Moll, and Cockerham, 1966). The expected mean squares are listed in table 1. The combined main effects of isolate MATA and isolate MATa determined the additive genetic variance and the MATA $\times$ MATa term defined the additive $\times$ additive genetic variance in the initial population and all selection generations.

\section{RESULTS}

\section{Initial population}

Matings among the initial population produced an overall mean of $44 \cdot 19$ perithecia per leaf disk with a standard error of $0 \cdot 59$. Genetic variation accounted for 79 per cent of the total variation in the initial population. Eight MATA isolates and four $M A T a$ isolates in this initial population had a defective allele at the perithecial locus (Leonard, 1978; Nelson, 1959b). Crosses in which both parents had the defective perithecial allele produced an average of $15 \cdot 79 \pm 0.68$ perithecia per leaf disk; crosses in which one parent had the perithecial allele produced an average $41 \cdot 09 \pm 0 \cdot 76$ perithecia per leaf disk; and crosses in which neither parent had the defective perithecial allele had an average of $72 \cdot 2 \pm 1.73$ perithecia per leaf disk. Thus, the perithecial allele appeared to act additively in the paired isolates to determine the number of perithecia per leaf disk. The perithecial locus accounted for 58 per cent of the genetic variation in the initial population, and the balance of the variation was accounted for by polygenic effects. Additive genetic variance (including the additive effects of the perithecial gene) accounted for 83 per cent of the genetic variation, with the rest of the genetic variation attributed to additive $x$ additive genetic variation.

\section{Response to selection}

The response to selection for increased numbers of perithecia over six generations is illustrated in fig. 1. The analysis of variance for each generation 


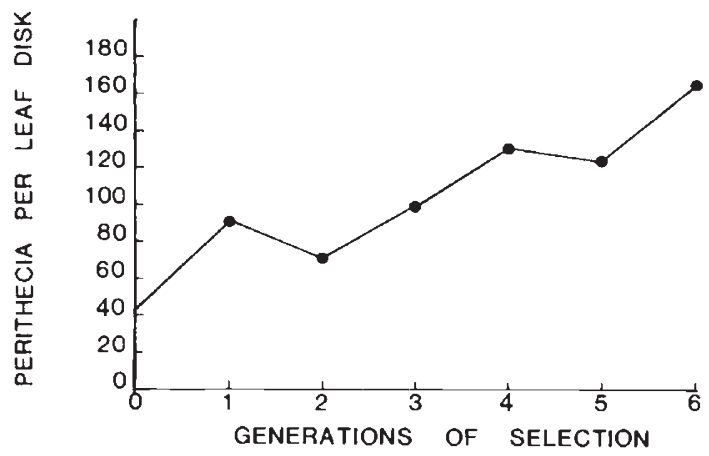

Figure 1 The response to selection based on additive genetic variance over six generations.

is presented in table 2 . The means, selection differentials, and components of genetic variation are presented in table 3 . With six cycles of selection the mean number of perithecia per leaf disk increased from 90 to 165 and the standard errors ranged from $0 \cdot 24$ to $3 \cdot 26$.

The selected isolates in the initial population all had the effective perithecial allele, thus fixing the allele in the subsequent selection generations. All selection after the first cycle utilised polygenic variation. The proportion of additive genetic variance relative to total genetic variance in the initial and selected populations decreased linearly from 0.83 , to 0.23 over the six generations (fig. 2).

\section{Evaluation of subpopulations in common environments}

Subpopulations consisting of isolates randomly sampled from the initial and selected populations were evaluated in three separate tests shown in fig. 3 . The standard errors of mean numbers of perithecia in the three tests ranged from $3 \cdot 2$ to $6 \cdot 6$. In general, the trend of increasing numbers of perithecia with succeeding generations of selection was
Table 2 North Carolina Design II. Analysis of variance for number of perithecia in initial and selection populations

\begin{tabular}{|c|c|c|c|}
\hline $\begin{array}{l}\text { Generation } \\
\text { of } \\
\text { selection }\end{array}$ & $\begin{array}{l}\text { Source } \\
\text { of } \\
\text { variation }\end{array}$ & d.f. & $\begin{array}{l}\text { Mean } \\
\text { square }\end{array}$ \\
\hline 0 & $\begin{array}{l}\text { Isolates } M A T A \\
\text { Isolates } M A T a \\
M A T A \times M A T a \\
\text { M.S.E. } \dagger\end{array}$ & $\begin{array}{r}12 \\
11 \\
120 \\
454\end{array}$ & $\begin{array}{c}14,084^{*} \\
13,026^{*} \\
614^{*} \\
216\end{array}$ \\
\hline 1 & $\begin{array}{l}\text { Isolates } M A T A \\
\text { Isolates } M A T a \\
M A T A \times M A T a \\
\text { M.S.E. }\end{array}$ & $\begin{array}{r}13 \\
11 \\
131 \\
457\end{array}$ & $\begin{array}{r}3,840^{*} \\
18,835^{*} \\
1,018^{*} \\
436\end{array}$ \\
\hline 2 & $\begin{array}{l}\text { Isolates } M A T A \\
\text { Isolates } M A T a \\
M A T A \times M A T a \\
\text { M.S.E. }\end{array}$ & $\begin{array}{r}14 \\
8 \\
107 \\
356\end{array}$ & $\begin{array}{c}7,196^{*} \\
9,775^{*} \\
1,347^{*} \\
748\end{array}$ \\
\hline 3 & $\begin{array}{l}\text { Isolates MATA } \\
\text { Isolates } M A T a \\
M A T A \times M A T a \\
\text { M.S.E. }\end{array}$ & $\begin{array}{r}12 \\
11 \\
127 \\
449\end{array}$ & $\begin{array}{r}5,084^{*} \\
13,628^{*} \\
1,735^{*} \\
842\end{array}$ \\
\hline 4 & $\begin{array}{l}\text { Isolates } M A T A \\
\text { Isolates } M A T a \\
M A T A \times M A T a \\
\text { M.S.E. }\end{array}$ & $\begin{array}{r}10 \\
10 \\
88 \\
315\end{array}$ & $\begin{array}{r}8,031^{*} \\
20,712^{*} \\
3,712^{*} \\
1,467\end{array}$ \\
\hline 5 & $\begin{array}{l}\text { Isolates MATA } \\
\text { Isolates MATa } \\
\text { MATA } \times M A T a \\
\text { M.S.E. }\end{array}$ & $\begin{array}{r}12 \\
10 \\
107 \\
394\end{array}$ & $\begin{array}{c}2,465^{*} \\
6,582^{*} \\
1,791^{*} \\
767\end{array}$ \\
\hline 6 & $\begin{array}{l}\text { Isolates MATA } \\
\text { Isolates } M A T a \\
M A T A \times M A T a \\
\text { M.S.E. }\end{array}$ & $\begin{array}{r}11 \\
6 \\
53 \\
210\end{array}$ & $\begin{array}{c}13,689^{*} \\
21,573^{*} \\
7,962^{*} \\
1,033\end{array}$ \\
\hline
\end{tabular}

* Significant at $0 \cdot 05$.

$\dagger$ Mean square error.

confirmed in these tests. In a separate test, subpopulations from generations one and five were evaluated in a common environment to estimate the difference in the number of effective factors influencing perithecial number between selected

Table 3 Means, selection differentials, and components of genetic variation of initial and selection generations

\begin{tabular}{lllll}
\hline $\begin{array}{l}\text { Generations } \\
\text { of } \\
\text { selection }\end{array}$ & $\begin{array}{l}\text { Mean number } \\
\text { of } \\
\text { perithecia/leaf disk }\end{array}$ & $\begin{array}{l}\text { Selection } \\
\text { differential }\end{array}$ & $\begin{array}{l}\text { Additive } \\
\text { genetic } \\
\text { variance }\end{array}$ & $\begin{array}{l}\text { Additive } \times \\
\text { additive } \\
\text { genetic } \\
\text { variance }\end{array}$ \\
\hline 0 & $44 \pm 0 \cdot 59$ & 20 & 539 & 99 \\
1 & $90 \pm 0 \cdot 84$ & 36 & 376 & 145 \\
2 & $71 \pm 0 \cdot 24$ & 30 & 392 & 149 \\
3 & $100 \pm 1 \cdot 18$ & 12 & 321 & 222 \\
4 & $129 \pm 3 \cdot 36$ & 10 & 484 & 561 \\
5 & $123 \pm 1 \cdot 21$ & 24 & 107 & 255 \\
6 & $165 \pm 1 \cdot 91$ & - & 513 & 1732 \\
\hline
\end{tabular}




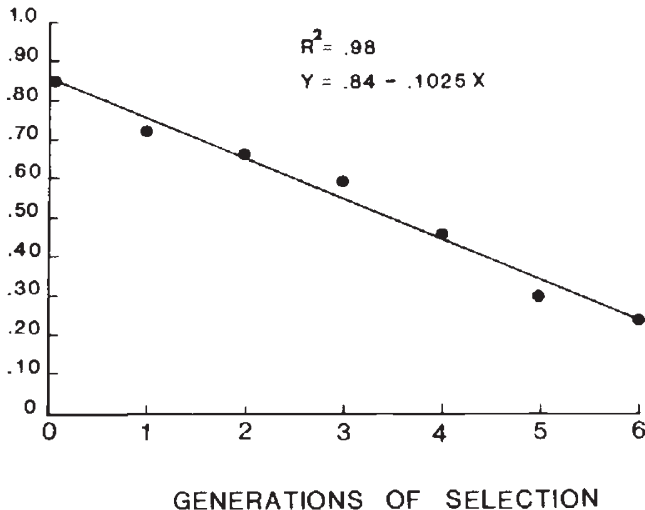

Figure 2 Change in additive genetic variance relative to total genetic variance over six generations of selection based on additive variance.

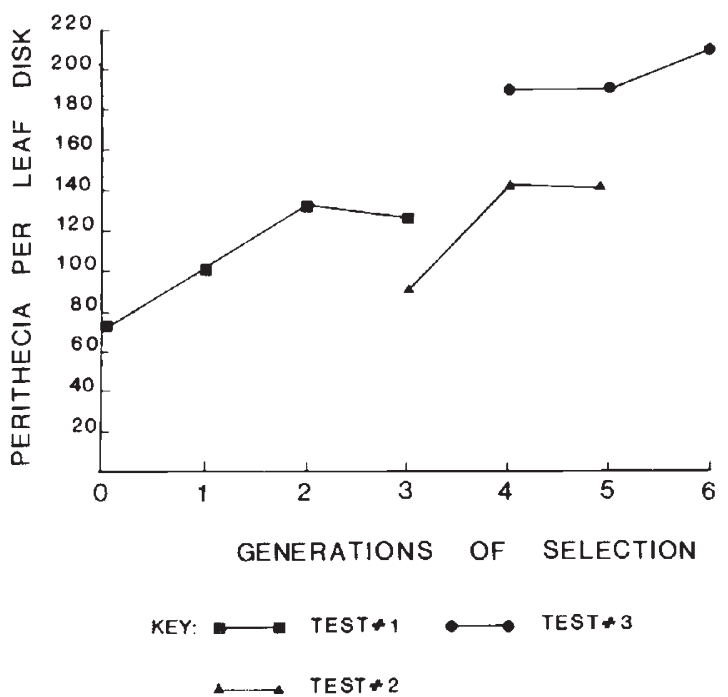

Figure 3 Evaluation of subpopulations in common environments from the initial population, and all selected generations in three separate tests.

isolates in these two generations. Two individual isolates from generations five and one had mean numbers of $203.5 \pm 9.27$ and $90.63 \pm 6.84$ perithecia per leaf disk, respectively. The combined estimate of additive genetic variance of 561 was obtained for the two generations. Burnett's (1975) formula for estimating the difference in number of effective factors in haploids, $1 / 4$ (High extremeLow extreme $)^{2} /$ Additive Genetic Variance, was used to calculate an estimated difference of 5.7 effective factors between isolates of generations one and five.

\section{DISCUSSION}

In our tests, the numbers of mature perithecia per leaf disk were determined to be under the control of the perithecial gene locus and polygenic effects. Nelson $(1959 b)$ described as recessive an allele that prevented perithecial production in Cochliobolus heterostrophus, however he did not quantitatively distinguish between the numbers of perithecia formed when one or both paired isolates had the effective perithecial allele. We have shown that the perithecial allele acted additively in determining numbers of perithecia.

The number of mature perithecia per leaf disk in matings among isolates from the sixth generation was nearly four times greater than the numbers in matings among isolates of the initial population. This increase is similar to selection gains in experiments with penicillin production in Aspergillus nidulans (Merrick, 1976) and growth rate in Neurospora crassa. (Papa, Srb, and Federer, 1966) and Schizophyllum commune (Simchen, 1966). A realised heritability estimate of 0.74 for the number of perithecia per leaf disk was obtained from the slope of the regression of the mean number of perithecia per generation on the accumulated selection differential (table 3) (Falconer, 1980). Because of the small population sizes, random fixation of some alleles affecting the number of perithecia could have occurred; however the intensity of selection should have been sufficient to transcend the effects of drift in increasing perithecial number. Perhaps with larger populations the decline in the proportion of additive genetic variance would have been less dramatic. We did not consider reverse selection for lower numbers of perithecia as fertility would be reduced to a level that would prohibit ascospore formation in the selected crosses.

The rate of increase in fertility appeared to be greater between the initial population and fourth selection generation than between the fourth and sixth generations (fig. 1). Continued selection for perithecial number should be possible since there is an appreciable proportion of additive genetic variance remaining in the sixth generation of selection. Our selection scheme, based on selecting the most fertile MATA isolates and the most fertile MATa isolates is similar to selection based in general combining ability (Falconer 1980). Both of these selection schemes act on additive genetic 
variance affecting the trait of interest. As the number of perithecia per leaf disk increased through the generations (fig. 1), the proportion of additive genetic variance decreased (fig. 2). The reduction in the proportion of additive genetic variance can be attributed to fixation of alleles affecting numbers of mature perithecia. In the later selection generations, additive $\times$ additive variance accounted for nearly all of the genetic variance present. This agrees with Simchen (1966) who observed a similar reduction in additive genetic variance among haploid lines of Schizophyllum commune in a population subjected to recurrent selection for rate of mycelial growth. In the population selected for high rate of mycelial growth, additive genetic variance decreased from 25 to zero within 10 generations. In the population selected for slow growth rate, additive genetic variance remained unchanged over the 10 generations.

Fluctuations in the apparent rates of increase of fertility (fig. 1) in our experiments as well as differences between different tests of isolates from the same generation (fig. 3) can be attributed to environmental variation. Specifically, different batches of Sach's agar and leaf disks used in different tests could have affected the expression of perithecial numbers. The three tests using subpopulations of different generations evaluated in common environments served as a control measure for the selection experiment. These experiments confirmed the trend of increasing numbers of perithecia with succeeding generations. The estimated difference of $5 \cdot 7$ effective factors influencing numbers of perithecia between generations one and five is consistent with the rapid increase in perithecial number due to selection, and the rapid decrease in additive genetic variance, both of which indicate that a relatively small number of polygenic units influence numbers of perithecia. Our estimate is similar to Simchen's (1966) estimates of effective factors for differences in growth rates between high and low selection lines of $S$. commune. His estimates ranged from $5 \cdot 5$ to $9 \cdot 29$ effective factors.

The sexual stage of $C$. heterostrophus can be induced readily in the laboratory, but it has rarely been found in nature. Reproduction of the fungus in nature is primarily asexual by wind-dispersed conidia. Although sexual reproduction seems to be unimportant in the life cycle and the levels of fertility among field isolates of $C$. heterostrophus are low, the fungus has retained polymorphisms for mating type and the major genes affecting perithecial production as well as quantitative variability. Circumstantial evidence indicates that at least some genetic recombination occurs in natural populations (Leonard, 1973) but other mechanisms such as heterokaryosis (Leach and Yoder, 1982) might account for it. The low fertility of wild-type isolates relative to that attained in our selected populations may reflect the limited opportunities for sexual reproduction to occur in nature. Perithecial production and maturation of ascospores are inhibited by exposure to light at even low intensities. Because it takes 3 weeks for production of mature ascospores, there are likely to be few situations in nature in which the process would not be interrupted before the perithecia or ascospores matured.

\section{REFERENCES}

BURNETT, J. H. 1975. Mycogenetics. John Wiley and Sons, London.

EBERHART, S. A., MOLL, R. H. AND COCKERHAM, C. C. 1966. Epistatic and other genetic variances in two varieties of maize. Crop Science, 6, 275-280.

FALCONER, D. S. 1980. Introduction to Quantitative Genetics. Longham Inc. New York.

KLINE, D. M. AND NELSON, R. R. 1968. Variation in mating capacities among 103 isolates of Cochliobolus sativus. Phytopathology, 58, 1055.

LEACH, J. AND YODER, O. C. 1982. Heterokaryosis in Cochliobolus heterostrophus. Experimental Mycology, 6, 364-374.

LEONARD, K. J. 1973. Association of mating types and virulence in Helminthosporium maydis, and observations on the origin of the race $T$ population in the United States. Phytopathology, 63, 112-115.

LEONARD, K. J. 1978. Polymorphisms for lesion type, fungicide tolerance, and mating capacity in Cochliobolus carbonum isolates pathogenic to corn. Can. J. Bot., 56, 1809-1815.

MERRICK, M. J. 1976. Hybridisation and selection for penicillin production in Aspergillus nidulans-a biometrical approach to strain improvement. In: Genetics of Industrial Microorganisms. Edited by K. D. MacDonald. Academic Press, New York.

NELSON, R. R. 1957. Heterothallism in Helminthosporium maydis. Phytopathology, 47, 191-192.

NELSON, R. R. 1959a. Genetics of Cochliobolus heterostrophus I. Variability in degree of compatibility. Mycologia Vol. Ll No. 1, pp. 18-23.

NELSON, R. R. 1959b. Genetics of Cochliobolus heterostrophus. IV. A mutant gene that prevents perithecial formation. Phytopathology, 49, 384-386.

NELSON, R. R. 1961. Evolution of sexuality and pathogenicity. II. A comparison of the pattern of sexuality in Cochlioblus victoriae and related species. Phytopathology, 51, 222-223.

NELSON, R. R. 1964. Inhibition of perithecial formation in Cochliobolus carbonum. Phytopathology, 54, 876-877.

NELSON, R. R. 1970. Variation in mating capacities among isolates of Cochliobolus carbonum, Can. J. Bot., 48, 261-263.

PAPA, K. E., SRB, A. M. ANI FEDERER, W. T. 1966. Selection for increased growth rate in inter- and intra-strain crosses of Neurospora. Heredity, 21, 595-613.

SIMCHEN, G. 1966. Monokaryotic variation and haploid selection in Schizophyllum commune. Heredity, 21, 241-263. 